06

\title{
Прямой динамический синтез нанодисперсных фаз оксидов титана при распылении электроразрядной плазмы титана в воздушную атмосферу
}

\author{
(ㄱ А.А. Сивков, Д.Ю. Герасимов, Д.С. Никитин \\ Национальный исследовательский Томский политехнический \\ университет, \\ " E-mail: NikitinDmSr@yandex.ru
}

Поступило в Редакцию 14 июня 2016 г.

Приведены экспериментальные исследования возможности прямого динамического синтеза нанодисперсных кристаллических фаз диоксидов титана со структурой рутила и анатаза в гиперскоростной струе электроэрозионной плазмы, генерируемой коаксиальным магнитоплазменным ускорителем с титановыми электродами. Получен порошкообразный продукт, содержащий наноразмерные полиморфные фазы диоксида титана со сферической формой частиц.

Актуальность проблемы получения оксидов титана обусловлена их широким применением при изготовлении термостойких пластических масс, при получении прочных пленок как армирующего наполнителя, в области фотокатализа и солнечной энергетики, в качестве катализатора в химическом и фармацевтическом производстве [1-3]. Широкое использование оксидов титана обусловливается высокой стабильностью, способностью к самоочистке, самодезинфекции, фотокаталитической активностью, противомикробными и антикоррозионными свойствами этих соединений [4-6].

Важной научной задачей является разработка методов прямого синтеза нанодисперсного оксида титана, поскольку в наноразмерном состоянии активность частиц оксида титана значительно увеличивается [7]. Синтез нанодисперсных кристаллических материалов возможен в высокоскоростной импульсной струе плотной электроэрозионной плазмы. Струя генерируется импульсным сильноточным (порядка $100 \mathrm{kA}$ ) коаксиальным магнитоплазменным ускорителем (КМПУ) эрозионного типа. 


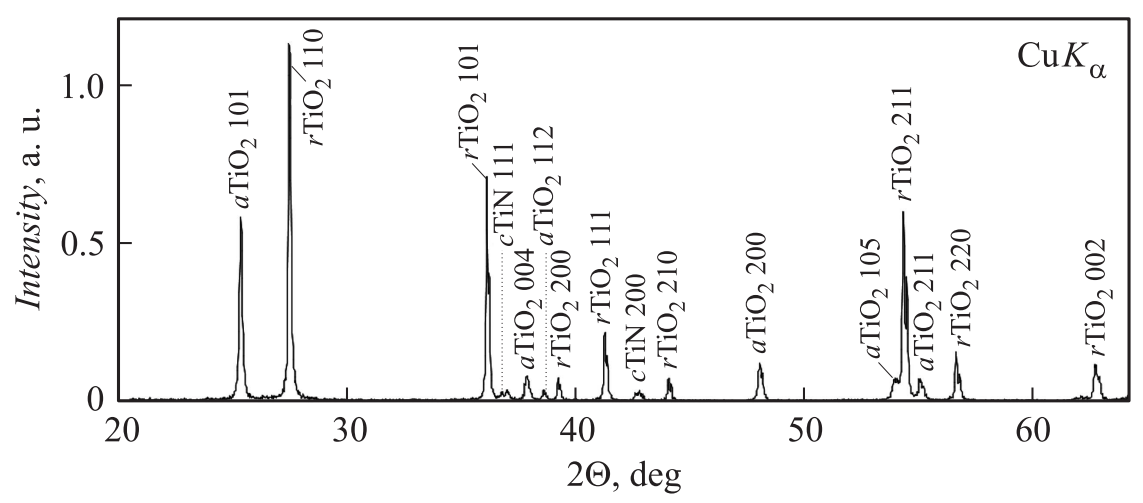

Рис. 1. Рентгеновская дифрактограмма порошкообразного продукта, полученного с помощью КМПУ с титановыми электродами в воздушной атмосфере.

Его конструкция базируется на классическом Z-пинч-ускорителе, основными элементами которого являются центральный электрод и электродствол с цилиндрическим ускорительным каналом (УК). Ускоритель называется эрозионным, потому что основной материал, необходимый для синтеза требуемого продукта, нарабатывается электроэрозионным путем с цилиндрической поверхности УК, по которой перемещаются опорные пятна ускоряемого сильноточного разряда типа Z-пинч [8]. Таким образом, задачей данной работы является реализация синтеза нанодисперсных оксидов титана в высокоскоростной импульсной струе плотной электроэрозионной плазмы.

Используемый метод является прямым, так как процесс полностью реализуется в одном кратковременном (порядка $1 \mathrm{~ms}$ ) цикле работы КМПУ. Основной расходный материал (титан) нарабатывается электроэрозионным путем с поверхности УК и в расплавленном состоянии захватывается ускоряемым разрядом. При температуре в несколько тысяч градусов он переходит в плазменное состояние, ускоряется до гиперзвуковых скоростей и выносится из УК в пространство цилиндрической камеры-реактора, заполненной воздухом. Электропитание КМПУ осуществляется от импульсного источника - емкостного накопителя энергии. 


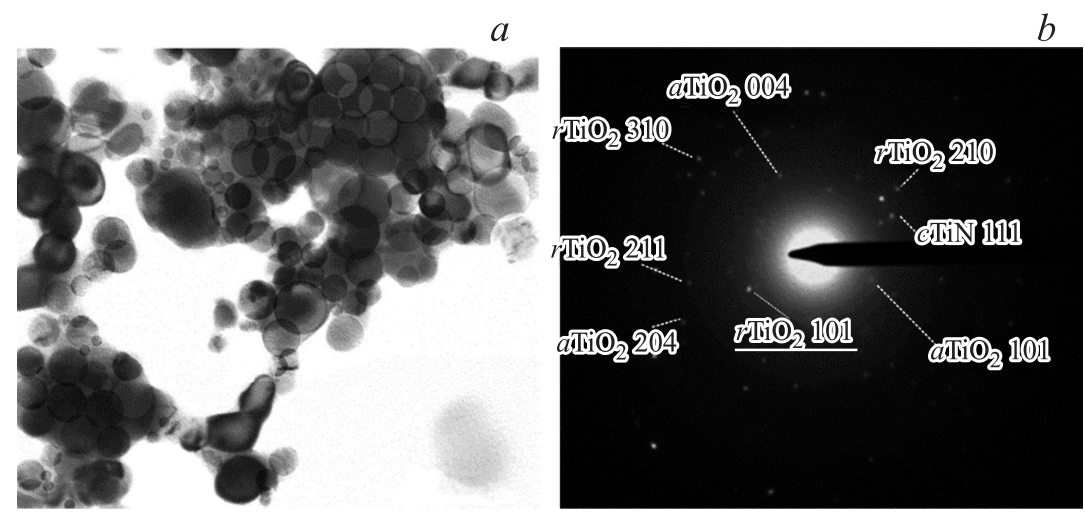

$200 \mathrm{~nm}$

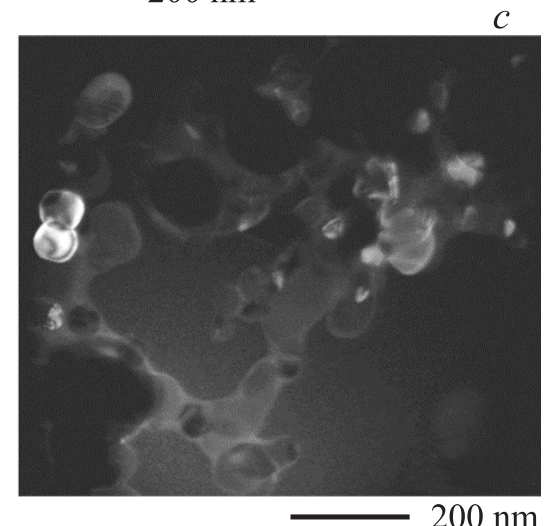

Рис. 2. Данные ТЕМ-исследований порошкообразного продукта, полученного в воздушной атмосфере: $a-$ светлопольный ТЕМ-снимок скопления частиц, $b$ - картина электронной дифракции соответствующего скопления, $c$ темнопольный ТЕМ-снимок, полученный в рефлексе $r \mathrm{TiO}_{2} 101$.

В работе [8] показано, что при заданных геометрии УК и материале электродов ускорителя основным фактором, определяющим величину эродированной массы $m$ и скорость плазменного течения $\vartheta$ на срезе УК, является величина подведенной и диссипированной в ускорительном канале энергии $W$. При этом величина удельного

Письма в ЖТФ, 2016, том 42, вып. 23 


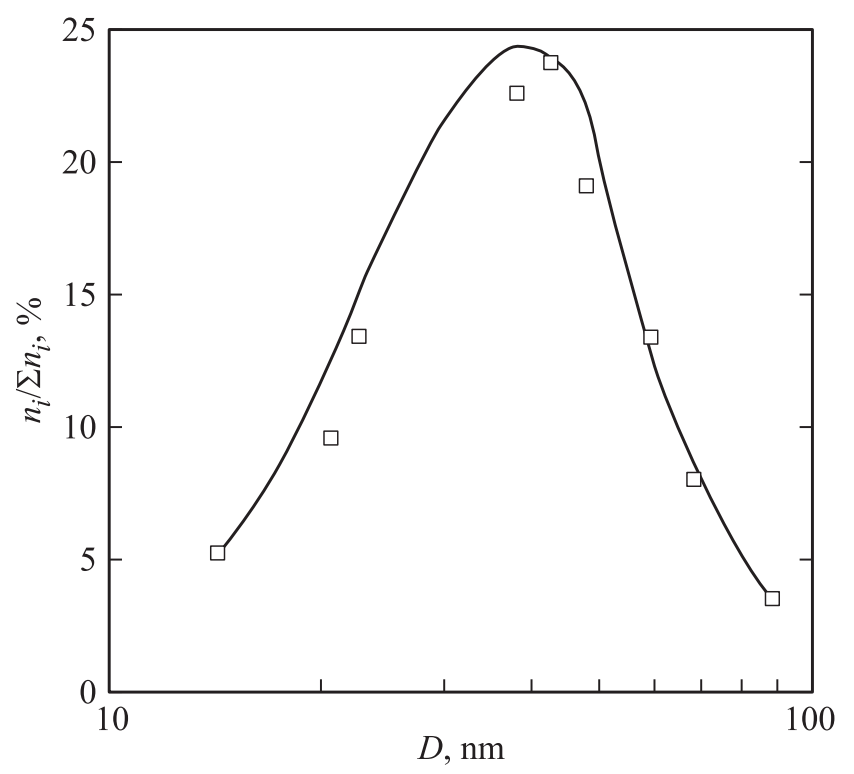

Рис. 3. Кривая распределения частиц диоксида титана по размерам в порошкообразном продукте динамического синтеза.

электроэрозионного износа $m / W$ прямо пропорциональна удельной подведенной энергии $W / V(V-$ объем УК). Подведенная в процессе эксперимента энергия определялась интегрированием кривой мощности разряда, полученной по осциллограммам тока $I(t)$ и напряжения $U(t)$ на электродах КМПУ. Вынесенная из УК масса $m$ определялась взвешиванием ствола до и после плазменного выстрела. Отбор полученного продукта динамического синтеза проводился через несколько часов после осаждения взвешенной фракции на стенки камеры-реактора при комнатной температуре. Аналитические исследования проводились с использованием методов рентгеновской дифрактометрии (Shimadzu $\mathrm{XRD7000,} \mathrm{CuK}_{\alpha}$ ) и просвечивающей электронной микроскопии (Philips CM 30).

Эксперименты по динамическому синтезу нанодисперсных кристаллических фаз оксида титана проведены на КМПУ с титановыми электродами. Центральный электрод ускорителя изготавливался из

Письма в ЖТФ, 2016, том 42, вып. 23 
Основные данные полнопрофильного структурно-фазового анализа продукта динамического синтеза, полученного с помощью КМПУ с титановыми электродами

\begin{tabular}{c|c|c|c|c|c}
\hline \multirow{2}{*}{$\begin{array}{c}\text { Кристаллическая } \\
\text { фаза }\end{array}$} & $\begin{array}{c}\text { Содержание, } \\
\text { mass \% }\end{array}$ & $\begin{array}{c}\text { OKP, } \\
\mathrm{nm}\end{array}$ & $\Delta d / d \cdot 10^{-3}$ & \multicolumn{2}{|c}{$\begin{array}{c}\text { Параметры решетки } \\
\text { экперимент/PDF4+, } \AA\end{array}$} \\
\cline { 4 - 6 } & 59 & 89 & 2.43 & $4.5959 / 4.5940$ & $2.9616 / 2.9590$ \\
$r \mathrm{TiO}_{2}$ & 39 & 48 & 3.28 & $3.7790 / 3.7970$ & $9.5697 / 9.5790$ \\
$a \mathrm{TiO}_{2}$ & 2 & 57 & 2.39 & $4.2388 / 4.2410$ & - \\
$c \mathrm{TiN}$ & &
\end{tabular}

титановой шпильки диаметром $18 \mathrm{~mm}$, а электрод-ствол — из титановой трубы с диаметром УК $d=21 \mathrm{~mm}$ и длиной $l=280 \mathrm{~mm}$. Эксперименты проведены в условиях истечения плазменной струи в камеру-реактор с воздушной атмосферой при нормальном давлении. Емкостный накопитель энергии $C=24 \mathrm{mF}$ заряжался до $U_{c h}=3.5 \mathrm{kV}$. При амплитуде импульса тока $I_{m}=230 \mathrm{kA}$ и подведенной энергии $W=94 \mathrm{~kJ}$ получен порошкообразный продукт белого цвета массой $m_{p}=9.3 \mathrm{~g}$. Осажденный порошкообразный продукт представлял собой рыхлый слой толщиной 5-6 mm. При сборе порошок проявляет тенденцию к агломерации, что характерно для нанопорошков [9].

На рис. 1 представлена типичная рентгеновская дифрактограмма, снятая на одной из проб порошкообразного материала. Ее характер свидетельствует об отсутствии аморфной фазы. Полнопрофильный структурно-фазовый анализ, основные результаты которого приведены в таблице, показал, что продукт динамического синтеза состоит примерно на 98\% из полиморфных кристаллических фаз диоксида титана: со структурой рутила $r \mathrm{TiO}_{2}-59 \%$ и анатаза $a \mathrm{TiO}_{2}-39 \%$. Так же в продукте идентифицируется фаза кубического нитрида титана $c \mathrm{TiN}$ при содержании не более $2 \%$.

Судя по среднему размеру области когерентного рассеяния (ОКР), полученный продукт можно отнести к нанодисперсным порошкам. Незначительные отклонения параметров решетки кристаллических фаз от теоретических значений (согласно международной базе PDF4+) обусловлены, по-видимому, высоким уровнем внутренних микронапряжений и высокой дефектностью структуры.

Письма в ЖТФ, 2016, том 42, вып. 23 
Данные рентгеновской дифрактометрии полностью подтверждаются результатами исследований методами просвечивающей электронной микроскопии (transmission electron microscopy - TEM), представленными на рис. 2. На ТЕМ-снимке (рис. 2, $a$ ) показано скопление частиц рассматриваемого продукта. Картина электронной дифракции на этом скоплении (рис. $2, b$ ) содержит множество рефлексов, соответствующих кристаллическим фазам $\mathrm{TiO}_{2}$, и отдельные рефлексы дифракции на плоскостях кубического нитрида титана $c$ TiN. Темнопольный снимок (рис. $2, c$ ) с двумя изображенными на нем частицами сферической формы получен в рефлексе $r \mathrm{TiO}_{2} 101$. Это дает дополнительные основания для идентификации сферических наночастиц как частиц диоксида титана. Анализ совокупности темнопольных ТЕМ-снимков, полученных в области рефлекса $c$ TiN 111, позволил отнести к этой фазе немногочисленные частицы многогранной, часто близкой к округлой, формы. Достоверность идентификации подтверждается и визуальной оценкой соотношения числа частиц идеальной сферической формы $\left(\mathrm{TiO}_{2}\right)$, которых значительно больше, и числа частиц многогранной (несферической) формы ( $c$ TiN).

По светлопольным ТЕМ-снимкам проведена оценка размеров частиц. Диапазон распределения по размерам составляет примерно $10-100 \mathrm{~nm}$ при законе распределения, близком к нормальному логарифмическому с максимумом в области примерно $50 \mathrm{~nm}$ (рис. 3). Результаты такой оценки хорошо совпадают с данными полнопрофильного структурно-фазового анализа по средним размерам ОКР (см. таблицу) идентифицированных фаз продукта, полученного с использованием КМПУ с титановыми электродами в воздушной атмосфере при нормальном давлении.

Проведенные экспериментальные исследования показали возможности метода с использованием системы на основе КМПУ с титановыми электродами по прямому динамическому синтезу нанодисперсных кристаллических фаз диоксидов титана со структурой рутила и анатаза в гиперскоростной струе электроэрозионной плазмы. При истечении титансодержащей плазменной струи в атмосферу воздуха синтезируются наноразмерные полиморфные фазы диоксида титана со сферической формой частиц.

Работа выполнена при финансовой поддержке Российского научного фонда (грант № 15-19-00049).

Письма в ЖТФ, 2016, том 42, вып. 23 


\section{Список литературы}

[1] Montazer M., Seifollahzadeh S. // Photochem. Photobiol. 2011. V. 87. P. 877883.

[2] Lian Z., Zhang Y., Zhao Y. // Innov. Food Sci. Emerg. Technol. 2016. V. 33. P. $145-153$.

[3] Zhou C.-W., Zhao J.-X., Liu Q. et al. // Int. Polym. Process. 2013. V. 28. P. 483488.

[4] Tong H., Ouyang S., Bi Y. et al. // Adv. Mater. 2012. V. 24. P. 229-251.

[5] Schilling K., Bradford B., Castelli D. et al. // Photochem. Photobiol. Sci. 2010. V. 9. P. 495-509.

[6] Seentrakoon B., Junhasavasdikul B., Chavasiri W. // Polym. Degrad. Stab. 2013. V. 98. P. 566-578.

[7] Пугачевский М.А. // Письма в ЖТФ. 2012. Т. 38. В. 24. С. 56-63.

[8] Gerasimov D.Y., Sivkov A.A. // J. Appl. Mech. Tech. Phys. 2012. V. 53. P. 140-146.

[9] Nur Y., Lead J.R., Baalousha M. // Sci. Total Environ. 2015. V. 535. P. 45-53. 